\title{
La política externa brasileña y la crisis en el Atlántico Sur: una evaluación
}

En el análisis de la política externa de un país conviene, analíticamente, tomar en cuenta dos dimensiones distintas, si bien complementarias. La primera se refiere a las normas de funcionamiento del orden mundial en un momento determinado. La segunda trata de clarificar la manera por la cual un país se inserta en la dinámica de funcionamiento del orden mundial, incluyéndose en el estudio de esta inserción sus relaciones bi- y multilaterales.

Creo que es importante efectuar un rápido análisis de estas dos dimensiones, como paso previo para una evaluación de la posición de la diplomacia brasileña en la reciente crisis del Atlántico Sur, que tuvo como epicentro la confrontación bélica entre Argentina y Gran Bretaña, provocada por el problema de las Malvinas.

I. Desde el punto de vista de la dinámica del funcionamiento del sistema internacional, me parece claro que hoy en día existe, en el plano mundial, un cisma entre orden y poder. El tradicional poder de gestación del sistema internacional, clásicamente ejercido por la acción de las gxandes potencias, está en crisis. Esta crisis se traduce, tanto en el plano estratégico diplomático cuanto en el campo económico, por la erosión del padrón de previsibilidad de las relaciones entre los diversos protagonistas de la vida internacional.

En el campo de las relaciones estratégico-diplomáticas se verifica igualmente una erosión de previsibilidad. Es cierto que las armas atómicas crearon un cierto tipo de equilibrio de terror, que hasta hoy se mantiene como el parámetro de la paz en escala mundial. Entre tanto, el uso de la fuerza armada en los contextos re-

NotA: Texto en que se basó la exposición efectuada por el autor en la mesa redonda sobre "Las relaciones internacionales de América Latina en los años 80", organizada por el RrAL durante el Decimosegundo Congreso Mundial de la International Political Science Association entre el 9 y el 13 de agosto de 1982, en Río de Janeiro. La traducción de las citas del Canciller Saraiva Guerreiro no es oficial. 
gionales ya no se ajusta a las normas y a las instancias formales e informales que, después de la segunda guerra, configuraron lo razonable para las grandes potencias en términos del conflicto EsteOeste. Existen conflictos, por ejemplo en el Medio Oriente, como es el caso de la guerra entre Irán e Irak e incluso la confrontación bélica entre Israel y la OLP en el Líbano, que sobrepasan la çapacidad de control de las grandes potencias o su poder disciplinario.

En un contexto de esta naturaleza, es evidente que se vuelve mucho más complejo lidiar con el conflicto, coordinar la reciprocidad de los intereses y promover la cooperación entre pueblos, países y economías. De ahí la ponderación del Canciller Saraiva Guerreiro en una reciente entrevista, cuando al discutir la permanente y necesaria negociación que se da entre países, disciplinada por el marco del Derecho Internacional Público, dice: "... hay una negociación constante a nivel técnico, que sólo puede existir porque hay un cuadro político que cubre esas negociaciones. Si se deteriorara ese cuadro político, éste acaba también influyendo en esas negociaciones". (Isto é I4 de julio de 1982, Nọ 290, p. 79).

En su exposición al Senado del 5 de mayo de 1982, dice también el Canciller Saraiva Guerreiro comentando la intensificación del conflicto de las Malvinas, el imperativo de detener el engranaje de la guerra y la concomitante carencia de recursos de poder disponibles para obtener una solución pacífica: "Nosotros no podemos imponer una solución pacífica. En rigor, nadie puede: el país más poderoso de la tierra lo intentó $\mathrm{y}$ hasta ahora no tuvo éxito". (Diario do Congresso Nacional, jueves 6 de mayo de 1982. p. 1396). Esta observación, pienso yo, trasciende el caso de las Malvinas y tiene el alcance de una evaluación objetiva sobre la actual distribución de poder en el mundo, unida a la disminución de la capacidad de gestión hegemónica del uso de la fuerza en conflictos entre estados por parte de las grandes potencias.

¿Cómo se inserta un país como el Brasil en un sistema internacional con las características ya anotadas?

A pesar de todas las dificultades por las cuales atraviesa nuestro país y de la delicada situación de sus cuentas externas que lo vuelven particularmente vulnerable a la dinámica del funcionamiento del sistema internacional, en particular en el campo económico financiero, parece evidente que en los últimos 15 años se verificó un significativo crecimiento económico, una expresiva profundización del proceso de industrialización y una gran diversificación, tanto de la pauta de exportaciones como de mercados externos. En conjunto, esto significa una alteración del peso y de la escala del Brasil en la vida internacional, que se convirtió, por así decir, en una potencia intermedia, o sea, como expresaba Giovanni Botero en su Della Region di Stato: ni tan sujeto a la violencia como los estados 
pequeños en virtud de su debilidad intrínseca, ni tan expuesto al énvejecimiento, como los grandes.

La siguiente es la apreciación del Canciller Saraiva Guerreiro: "El Brasil ya no es un país tan marginal; ninguna actitud ni iniciativa que tome pueden ser vistas como irrelevantes. Sabemos que cuando tomamos una posición, ella tiene una repercusión política y diplomática. Justamente el hecho de que el país ya no sea marginal, que tenga una posición dentro del contexto regional y mundial que no es irrelevante, es lo que lo lleva a un mayor cuidado en su comportamiento". (İsto é, 14 de julio de 1982, No 290, p. 78).

¿Cuál es la razón de este cuidado en materia de comportamiento externo, de esta prudencia que los especialistas consideran como una característica típica de la política exterior de países intermedios? Explica el Canciller Saraiva Guerreiro: "... para un país como el Brasil, que no tiene un excedente de poder ni un excedente de atracción cultural, económico o político, es indispensable que la política externa sea confiable". (Isto é, julio 14 de 1982, No 290, página 77) .

Esta afirmación de la inmportancia de la confiabilidad es una elección en materia de estilo diplomático. Como se sabe, los estilos diplomáticos son modalidades de actuación que, cuando se combinan y emplean bien, refuerzan - y cuando son mal utilizadas comprometen - a la acción estratégica de un país en el sistema internacional.

El Brasil no es un país que posee un excedente de recursos de poder, como las grandes potencias, ni tiene como ellas el objetivo estratégico de recuperar, en nuevos términos, la capacidad de gestión hegemónica de orden mundial. Por otro lado, el Brasil no se encuentra en la situación de los países débiles que, viviendo bajo el peso de condicionamientos de todo orden, quedan casi sin alternativas de actuación diplomática, careciendo de recursos de poder, lo que les impide alcanzar sus objetivos de transformación del sistema internacional.

En la presente estratificación internacional, el Brasil es un país intermedio, y como sus congéneres, posee algunos recursos de poder y cuenta en su activo diplomático con recursos polfticos y económicos. Por eso mismo, en conjunto con otros protagonistas del sistema interestatal, está en condiciones de desempeñar un cierto tipo de papel en la vida internacional.

En el actual momento internacional, pienso que se encuentra en el horizonte de lo posible de la acción diplomática de las potencias intermedias: i) buscar evitar el conflicto en el sistema interestatal, contribuyendo a la paz; ii) ayudar a llenar el vacío y a disminuir la laguna entre países ricos y pobres y iii) promover la 
cooperación internacional, sirviendo de puente entre culturas y civilizaciones.

En otras palabras, en la formulación oficial de la Cancillería brasileña: "El perfeccionamiento de la buena convivencia internacional es una tarea tan compleja cuanto destructiva y necesaria", pues "... el proceso de diversificación de intereses ya avanzó tanto en el plano internacional que no parece que el mecanismo simplificador representado. por la confrontación" (entre las potencias principales) "pueda subsistir sin que las tendencias en el sentido de la moderación y de la condposición luego se reafirmen. Por lo tanto, las alternativas a la confrontación merecen atención permanente". (Conferencia del Ministro Ramiro Saraiva Guerreiro en Ia Escuela Superior de Guerra, Rio de Janeiro, septiembre 4 de 1981, 47 y 39 , respectivamente).

Las alternativas a la confrontación exigen, por parte de las potencias intermedias, un cierto tipo de actuación que requiere credibilidad, tanto en relación a las grandes potencias cuanto en relación a los países débiles. No es fácil la búsqueda de la mantención de esta credibilidad. Exige gran competencia diplomática, puesto que la posición de las potencias intermedias, al ejercer las funciones moderadoras ya mencionadas, tropieza de un lado con las ambiciones de reconstitución de poder de las grandes potencias y del otro, con la urgencia, combinada con impotencia, de los países débiles en obtener significativas transformaciones del sistema internacional. De ahí el cuidado del que habla el Canciller Saraiva Guerreiro, pues en la presente coyuntura, la diplomacia de un pais intermedio debe transmitir consistentemente la ratio de moderación combinada con la voluntas de cambio, ambas necesarias para construir pacificamente un sistema internacional compatible con los nuevos imperatiros y las nuevas realidades del mundo en lá década del 80.

Evidentemente, la credibilidad no se agota en el cuidado del estilo diplomático. Ella requiere igualmente una correspondencia efectiva entre estilo y sustancia; una compatibilidad entre el cuadro interno de las necesidades del país y el cuadro externo de su actuación diplomática. En el caso del Brasil, creo que esta compatibilidad efectivamente existe.

La gran demanda brasileña de cooperación internacional en la década del 80 , necesaria para encaminar los problemas internos del país, no puede ser atendida por los esquemas bilaterales o multilaterales actualmente existentes. De ahí la voluntas de transformación presentada en los siguientes términos por la Cancillería brasileña: "Somos un país en desarrollo que necesita superar los obstáculos a la afirmación nacional y al desarrollo. La mantención de las actuales condiciones internacionales nos es nociva". (CF. confe- 
rencia del Ministro Ramiro Saraiva Guerreiro en la Escuela Superior de Guerra, el 4 de septiembre de 1981, 51).

Entretanto, como existen algunas ganancias relativas palpables del Brasil en la actual estructura de la estratificación internacional, éstas aconsejan la ratio de la moderación. Por otro lado, cabe decir que estas ganancias relativas, a pesar de palpables, son modestas. Los recursos de poder del Brasil son escasos. Por eso, Ios objetivos brasileños no pueden ser alcanzados aisladamente, requi- · riendo una acción conjunta con otros protagonistas de la vida internacional para hacer viable una estrategia de inserción diplomática en el camino hacia el proceso de transformación del sistema internacional. En las palabras del Canciller Saraiva Guerreiro: "Nuestro papel internacional es constructivo. Favorecemos siempre la creación de confianza, la obtención del entendimiento justo, la promoción del progreso y cle las ventajas recíprocas, la superación del egoísmo por la cooperación. Contrariamos los privilegios de grupos restringidos de Estados". (Conferencia en la Escuela Superior de Guerra, el 4 de septiembre de 1981, 52).

En conjunto, esto es todo lo que justifica la elección del estilo diplomático y explica los cuidados y la preocupación con la credibilidad de Itamaraty, ya mencionados, que en el caso de las MaIvinas los hicieron "... evaluar, medir casi milimétricamente los pasos a dar", conscientes de que "el país es parte de un contexto internacional. Tiene que negociar, tiene que ver cuáles son aqueIlos puntos de conciliación. En los casos más concretos, tienen que ver cuál es el punto máximo en que puede obtener una satisfacción de sus intereses, satisfacción que, en la evaluación de la Cancillería, no transita ni por el estilo de la truculencia ni por el de las ilusiones del "hace de cuenta", pero sí por el de la responsabilidad (Canciller Saraiva Guerreiro, entrevista en Isto $\dot{e}$, julio 14 de 1982, No 290, pp. 76, 77 y 79 , respectivamente) .

II. A la luz de las reflexiones y del análisis ya propuestas, ¿cómo se puede examinar $y$ evaluar la conducción de la Diplomacia brasileña en la crisis de las Malvinas?

Evidentemente existe, como condición del éxito de la política exterior brasileña, una valorización de su contexto contiguo (los países vecinos) y de su contexto regional (el sistema latinoamericano), que requiere al mismo tiempo apertura en relación al mundo como un todo.

Observó el Canciller Saraiva Guerreiro que la posición del Brasil "tenía que ser una posición que refiejase nuestra situación latinoamericana, nuestras excelentes relaciones con Argentina, nuestra preocupación con la región". (Exposición en el Senado Federal el 
5 de mayo de 1982, en Diario do Congresso Nacional, jueves 6 de mayo 1982, p. 1394).

La densidad - pasada, presente y futura- de las relaciones del Brasil con Argentina, una potencia intermedia como nuestro país y la llave para cualquiera política exitosa brasileña-latinoamericana, explica por qué de parte del Brasil no hubo equidistancia. También explica la razón por la cual, en el esfuerzo diplomático de pacificación, Itamaraty no entró en el examen y en la calificación jurídica del uso de fuerza por parte de Argentina, prefiriendo dar "énfasis a una evolución pacífica de la situación, sin manifestarnos sobre el hecho en si". (Ganciller Saraiva Guerreiro, exposición en el Senado Federal el 5 de mayo de 1982 en Diario do Congresso Nacional, jueves 6 de mayo de 1982, p. 1399).

El Reino Unido - uno de los grandes centros financieros del mundo- era y es, en las palabras del Canciller Saraiva Guerreiro, un "país con el cual no tenemos la más mínima controversia, y con el cual tenemos relaciones sin problemas". (Isto é, 14 de julio de 1982, No 290, p. 77). De ahí se desprende una de las razones por las cuales durante la crisis no hubo un alineamiento absoluto del Brásil en relación a Argentina, pero sin un esfuerzo "en el sentido de circunscribir los efectos negativos que acarreaba el conflicto en si mismo, ya regionalmente, ya en un punto de vista más general". (Isto é, 14 de julio de 1982, No 290, p. 76).

Este esfuerzo moderador exigía credibilidad, obtenida en primer Iugar por la actuación-diplomática responsable, traducida en “jamás hemos escondido los contactos con una u otra parte, o lo que pensábamos. Nunca dijimos a nadie una cosa diferente de la que habíamos dicho al otro". (Isto é, julio 14 de 1982, No 290, p. 76).

El estilo de esta actuación diplomática combina sustantivamente la ratio de moderación con la voluntas de transformación. De allí surgió en el transcurso de la crisis la crítica brasileña a actitudes y medidas que herian a Argentina, a la vez que constituian graves precedentes en el Conflicto Norte-Sur, contrarios a los intereses del Brasil, de América Latina y del Tercer Mrundo. En verdad, algunas de estas medidas significaron un alineamiento automático de los países desarrollados de mercado, en un esfuerzo de reconstrucción del poder del Norte en el plano mundial. Es el caso de las sanciones económicas contra Argentina que obtuvo el Reino Unido, primero de la Comunidad Económica Europea y después de los Estados Unidos. Estas fueron encaradas por el Brasil como medidas económicas agresivas tomadas por países ajenos a la controversia y sin apoyo en las normas y prácticas del Derecho Internacional, puesto que no tenian fundamento ni en el GATT, ni en la Carta de la onu, ni tampoco en la Resolución 502 del Consejo de Seguridad (Gf. Exposición del Canciller Saraiva Guerreiro en 
el Senado en Diario do Congresso Nacional, jueves 6 de mayo de 1982).

La posición brasileña, jurídicamente impecable, fue en el sentido de insistir en el carácter obligatorio de la Resolución 502 det Consejo de Seguridad, tomada en el cuadro del capítulo vir de la Carta de las Naciones Unidas que, en cuanto tal, a partir de su adopción, invalidaba los alegatos de legitima defensa (Art. 51 de la Carta), tanto de Argentina cuanto del Reino Unido.

Esta insistencia se verificó inclusive en el plano multilateral, en el contexto de la solidaridad latinoamericana. En la reunión de consulta del Tratado Interamericano de Asistencia Recíproca, el Brasil contribuyó a recalcar la unidad indisoluble de los tres aspectos de la Resolución 502: cesación de hostilidades, retirada de las tropas argentinas y negociación.

Esta insistencia, además de jurídicamente correcta, fue también políticamente sabia y responsable; esto último porque tenía como objetivo, al destacar la importancia de los medios pacíficos de solución de controversia, salvaguardar urbi et orbi la tradición diplomática brasileña de condenación del uso de la fuerza en el plano internacional. Esta condenación del uso de la fuerza no fue formulada de manera abstracta ni formal; tomaba en cuenta los derechos argentinos que siempre, y consistentemente, sustentó el Brasil. En las palabras precisas del Canciller Saraiva Guerreiro: "En verdad, desde el comienzo se han acentuado dos puntos. Uno es que, ya en el año 1833, cuando Gran Bretaña ocupó por la fuerza las Malvinas, expulsando al gobernador argentino, el gobierno argentino informó de ello al gobierno imperial, al gobierno brasileño, a la Regencia, e instruyó a su Ministro Plenipotenciario en Londrés a secundar las gestiones de protesta del representante argentino.

"Desde entonces, nunca hubo un laudo arbitral, sentencia jurídica internacional o tratado que diese validez jurídica erga omnes, para todos, a esa ocupación de las Malvinas. $Y$ el propio transcurso del plazo no confirió a esa situación de hecho de un valor jurídico incontrovertible, puesto que el país perjudicado mantuvo en estos 149 años actitud de protesta y reclamo, sin interrupción.

"Durante 17 años, desde 1965, la Organización de las Naciones Unidas se ocupa del asunto. Hay varias Resoluciones: 3 principales, en el cuadro del gran tema de la descolonización: una tomada en 1965; otra, en 1973; otra en 1976 por la Asamblea General de las Naciones Unidas, en que sè recomienda a las partes la negociación. El Brasil votó a favor de esas resoluciones y nunca se llegó a un resultado apreciable.

"Nuestra gran preocupación, como la de todo el mundo ahora, es detener el engranaje de violencia y ver si podemos revertir ese 
proceso y volver a un cuadro de negociaciones dentro de un esplritu de conciliación, de justicia. Todo lo que hemos hecho y procurado hacer, desde entonces, no escapa a este objetivo; eso explica esencialmente cuál es nuestro espíritu". (Exposición del CanciIler Saraiva Guerreiro en el Senado Federal en Diario do Congresso Nacional, jueves 6 de mayo de 1982, p. 1393).

Esta postura explica las razones por las cuales el Brasil no adoptó en la controversia de las Malvinas la actitud de "neturalidad absoluta" que reclamaban algunos criticos de la política exterior brasileña. En la línea de ratio de moderación combinada con la voluntas de transformación, el Brasil valorizó su relación con Argentina y su preocupación por la región y por la paz, mostrando que la Resolución 502 no significaba una vuelta al "status quo ante", puesto que la resolución preveĺa la negociación entre las partes (Cf. Exposición del Canciller Saraiva Guerreiro en el Senado Federal en Diario do Congresso Nacional, jueves 6 de mayo de 1982, p. 1400). En el entendèr del Canciller Saraiva Guerreiro, ésta era indispensable, pues no se resuelven "las cuestiones en el ámbito internacional, a no ser en caso extremo, con soluciones mecánicas no soluciones militares, aunque veamos que esa ilusión vuelve a surgir a cada momento". (Isto é, julio 14 de 1982, No 290, p. 78).

El desenlace de la crisis, con la victoria militar de Gran Bretaña, trajo momentáneamente una paz de poder para el Atlántico Sur. Esta paz es inestable, porque tiene como nota típica sólo la ausencia de guerra, y es el producto de la coalición preponderante de fuerzas que Gran Bretaña, con el apoyo de los Estados Unidos, consiguió movilizar contra Argentina. Ella no resulta de la confianza recíproca, pues la controversia permaneció en el cuadro de un sistema interamericano en crisis, agudizada por el alineamiento de los Estados Unidos con Gran Bretaña.

En efecto, a pesar de la indiscutible importancia que revisten los Estados Unidos para América Latina, la verdad es que, en el momento de la profundización de la crisis, la diplomacia norteamericana reconsideró sus caminos: dejó de tratar de detener el engranaje de la guerra y reafirmó con su apoyo los lazos con el Reino Unido, con todo lo que eso significa en el campo de las relaciones Este-Oeste y Norte-Sur.

En este contexto se evidencian las inconsistencias del sistema interamericano construido después de la segunda guerra, basado en un amplio círculo de intereses, valores y recursos de poder de los Estados Unidos, de alcance planetario, en el ámbito del cual se inscribieron los intereses, los valores propios y los recursos de poder de los países latinoamericanos. En la presente coyuntura internacional, señalada por la escición entre orden y poder, estos supuestos desaparecerán con el deterioro del cuadro político y económico en 
el cual tuvieron origen. En la expresiva formulación de Helio Jaguaribe, "La OEA perdió legitimidad porque perdió representatividad. Y el TIAR perdió viabilidad porque los enemigos dejaron de ser comunes en el ámbito interamericano." (Flelio Jaguaribe, Reflexiones sobre el Atlántico Sur, Folha de Sao Paulo, 26 de junio de 1982, p. 3).

Durante la crisis de las Malvinas el Brasil consiguió con gran éxito contribuir a "circunscribir los efectos negativos del conflicto", éxito que debe ser acreditado a la gran competencia diplomática de la cancillería brasileña, y que ahora tiene la tarea de contribuir a circunscribir los efectos negativos de "una solución mecánica".

En el caso específico de las Malvinas ésta significa, en los planos bi y multilateral, la reiteración de la posición brasileña tanto en relación a los derechos argentinos en el ámbito del gran proceso mundial de colonización cuanto la necesidad de una solución negociada para el problema, como medio de superar la inestabilidad de la actual paz y poder.

Es evidente que una paz satisfactoria, que sea negociada, transita por los intereses de Gran Bretaña. Requiere, igualmente, una adecuada tutela juridica de los derechos de cerca de 1.800 habitantes británicos de las islas, parte significativa de los cuales constituyen una población fluctuante, funcionarios del gobierno inglés o de la Falkland Island Co. Creo que, en el horizonte de una visión jurídico-política, atenta a la lógica de lo razonable y en consonancia con los hechos y valores que están actualmente en juego en el escenario mundial -inclusive el tema de la descolonización- el camino de esta tutela no pasa por el principio de autodeterminación de los pueblos del Derecho Internacional Público. Se trata de problemas y temas que, por su escala, se ajustan mejor a los principios del Derecho Internacional Privado.

En el caso de los efectos más amplios provocados por la "solución mecánica", cabe lidiar con la erosión del molde institucional del sistema interamericano. "Es evidente y es un hecho político la existencia, de hecho, de una crisis del sistema. Basta ver las diversas declaraciones de países del continente. $\mathrm{Y}$ una crisis no significa necesariamente el estancamiento", observó el Canciller Saraiva Guerreiro en su exposición al Senado Federal (En Diario del Congresso Nacional, jueves 6 de mayo de 1982, p. 1401).

¿Cuál es la razón de esta preocupación y por qué debe ser ella insertada en la agenda de una diplomacia que combina la ratio de la moderación con la voluntas de la transformación? ¿Por qué América Latina, como señaló Helio Jaguaribe, con la erosión de las instituciones básicas y del Sistema Interamericano se ve enfrentada con la falta de instrumentos e instituciones apropiadas para 
preservar sus intereses y valores frente al clivaje Este-Oeste y Norte-Sur que divide el mundo?

La crisis de las Malvinas evidenció la vulnerabilidad de los paises latinoamericanos, que están expuestos a fuerzas mundiales extremadamente poderosas que ninguno de ellos puede enfrentar, ni en conjunto ni aisladamente. Estados nacionales como Gran Bretaña, además de disponer de poder propio muy superior al de cualquier país latinoamericano, se encuentran también protegidos por sistemas de cooperación colectiva (NATO, MCE, OECD), que continúan siendo eficaces y que multiplican sus potencialidades económicomilitares (Gf. Helio Jaguaribe, "Reflexiones sobre el Atlántico Sur" (2) Folha de São Paulo, jueves 10 de julio de 1982, p. 3).

En este contexto, el primer punto que debe ser recalcado es la misma idea de una intensificación de la cooperación y del entendimiento dentro de la propia América Latina. (Gf. Canciller Saraiva Guerreiro, entrevista a (Isto é, julio 14 de 1982, No 290, p. 78) . En efecto, la crisis demostró que las potencialidades de los países desarrollados están en la línea de reconstrucción oligárquica de poder en el plano mundial. Estas potencialidades se sustentan inclusive por las características de actuación de la URss.

Sin ninguna duda, la uRss experimento en la última década un crecimiento expresivo de su poder mundial, que ofrece a este país nuevas oportunidades de participar en la conducción y el encaminamiento de las controversias y tensiones internacionales. Esta expansión es balanceada por la prudencia de una gran potencia que disminuyó su impacto revolucionario y que está interesada en mantener su posición en el sistema internacional. Por eso, prefiere explorar situaciones que ofrecen bajos riesgos y altas oportunidades, como es el caso de Angola, Yemen, Vietnam e incluso Afganistán.

América Latina, por una serie de circunstancias, entre las cuales cabe mencionar su pasado histórico y su actual contexto geográfico y político, no se amolda fácilmente a estas situaciones que ya hemos descrito, que muestran lo complicado de un conflicto NorteSur en el imponderable de una confrontación Este-Oeste.

La misma conducta de Argentina de la crisis de las Malvinas confirma esta observación. Este es un hecho objetivo de la realidad internacional en el ámbito del conflicto Este-Oeste, que debe ser tomado en cuenta por el Brasil y por América Latina en el contexto de las relaciones Norte-Sur.

En este sentido, termino reafirmando que al Brasil y a las potencias intermedias les cabe un papel en la coyuntura actual: 1) el de tratar de evitar que las potencialidades de reconstitución de poder del Norte desarrollado se encaminen hacia nuevas modalidades de gestión oligárquica de orden mundial; y 2) el de contribuir a 
que, en las paradojas de la situación actual, se descubran nuevas modalidades de acción conjunta que, bajo el signo de la equidad y de la democracia, lleven a la elaboración de adecuados padrones de lo responsable y de lo irresponsable, de lo lícito y lo ilícito, que eviten además el riesgo de anarquía que amenaza a la paz mundial. 